\title{
Estratégia e Ecologia: Um Estudo de Caso
}

\author{
Valmir Emil Hoffmann, M.Sc. \\ Universidade do Vale do Itajai - UNIVALI \\ Rua Santos Dumont, 1439 88350-000 Brusque/SC \\ e-mail: hoffmann@cia.com.br
}

\section{Resumo}

Com a Revoluçāo Industrial, o uso dos recursos naturais sofreu um grande incremento.

Devido sua limitaçáo, a necessidade de lidar com o desenvolvimento e com a preservação do meio ambiente ecológioo cria uma das questōes mais importantes da atualidade. Assim sendo, a relação entre as empresas e o meio ambiente é o ponto chave para se tentar atenuar o impacto do homem sobre a natureza.

O efeito da globalização faz com que a dimensāo ecológica, que já possuía interesse global, ganhe força, a ponto das naçōes mais desenvolvidas encontrarem na defesa da ecologia, uma barreira conveniente aos produtos concorrentes em seus mercados.

Dentro desse contexto, as empresas brasileiras buscam alternativas, tanto para atender a intensa fiscalizaçāo governamental, dentro do Brasil, como também para continuar participando da competiçāo naqueles mercados mais desenvolvidos, onde as harreiras nāo tarifárias, de apelo ecológico, bloqueiam 0 ingresso de seus produtos.

O caso da Hering Têxtil, uma das mais importantes industrias têxteis do mundo, é apresentado. A empresa é um referencial relevante dentro dessa discussão. A relação da empresa com a variável ecológica e sua visāo estratégica são consideradas com vistas a elucidar a maneira como ela tem tratado a questäo, tanto como ameaça quanto como oportunidade.

\section{Abstract}

With the Industrial Revolution, the use of natural resources has improved a lot. Because their limitation, the necessity of dealing with development and enviromental preservation creates one of the most important question of nowadays. Then the relation between enterprises and environment is a key point to try to decrease the impact of man over natural enviroment. The case of Hering Têxtil, one of the most important textil industries worldwide, is presented. Its relation with enviroment and the strategic view is considered.

\section{Key words:}

1.Ecology 2. Ecologic variable. 3.Ecologic administration. 4.Strategic planning. 


\section{Palavras iniciais}

A Revolução Industrial serviu, em um segundo momento, para alavancar as condiçōes de vida da população em muitas sociedades do hemisfério norte. Como conseqüência desse desenvolvimento houve também uma grande aceleração no uso dos recursos naturais. Assim como afirmam Delazaro \& Barbieri (1994:74), esse passo levou a depauperaçāo de recursos, e à degradação e destruição do meio ambiente.

O setor industrial, em grande parte, tem sido consumidor desses recursos. Como assinalado por Maimon (1994:120), o impacto do setor industrial na deterioração ambiental é significativo, ainda que tenha sido reduzido nos últimos 20 anos.

Margalef (1991) afirma que o metabolismo biológico corresponde à apenas $12 \%$ do total de energia gasta. Isso significa que a maior parte da enengia está sendo consumida de maneira alheia à manutenção essencial da vida. Há um processo de exaustação de recursos, a maioria deles concentrados em países do terceiro mundo, como constatam Delazaro \& Barbieri (1994).

Parece que esse processo de exaustação e consumo de recursos está preso às percepções coletivas sobre aquilo que é público e aquilo que é privado. Os bens considerados públicos têm um tratamento bastante diverso daquele obtido pelos privados. Na atual conjuntura, a idealização daquilo que é público faz com que ele não seja respeitado e sim se tente tirar dele algum proveito. Há a transformação daquilo que é público, como o ar puro, por exemplo, em privado, com a emanação de gases ácidos e outras toxinas.

Da mesma forma que se transforma uma propriedade desocupada, em um terreno baldio. Ocupa-se o espaço com o depósito de entulhos e lixos, dentro da noção de que aquilo que está desocupado pode ser ocupado. Isto é, aquilo que é público pode ser privado. Há uma falta de percepção quanto às dimensões e limites entre o que seja público e o seja privado.

Algumas medidas têm sido tomadas com relação à preservação da natureza enquanto bem público. Entre essas medidas, pode-se destacar a implantação de parques e reservas nacionais. Mas, como salienta Dajoz (1983:459) (...) a proteção da natureza, para ser eficaz, deve-se estender a todo o país. Nāo adiantaria nada proteger algumas zonas se o resto do território puder ser submetido a toda espécie de degradaçōes.(...) A proteção da natureza só estará verdadeiramente assegurada quando o público interno se tornar guardião decidido dela em todo o território.

Como se pode perceber, a questão é bastante complexa. A discussão concernente a variável ecológica transcende os a mbientes políticos, para ser tratada a nível empresarial. Em parte isso se deve ao efeito da globalização. Na prática, a globalização sempre existiu. O planeta, usando os conceitos de Senge (1995), é um grande sistema, interligado por várias conexōes. Ignorar esse fato é comprometer não só o consumo futuro, mas ta mbém a própria vida futura.

O caso apresentado por este artigo foi pesquisado utilizando-se uma metodologia 
qualitativa. Como recomendam vários autores, entre eles Alves (1991), Alves (1988?) e Godoy ( 1995; 1995a; 1995b), esse tipo de metodologia é mais apropriada no estudo de questóes organizacionais, que procurem entender processos. Foram efetuadas entrevistas do tipo não dirigida, usando a classificação descrita por Richardson (1985), com gerentes de várias áreas da empresa. Além disso, utilizou-se pesquisa bilbiográfica e documental como suporte às idéias destacadas.

\section{A Variável Ecológica}

Por uma questão eminentemente metodológica, é mister definir a amplitude que se quer dar para o termo variável ecológica. Nesse aspecto, usa-se a explanação feita por Dajoz (1983:27) para fator ecológico, como sendo todo elemento do meio susceptível de agir diretamente sobre os seres vivos, ao menos durante a primeira fase de seu ciclo de desenvolvimento, pode ser bastante útil. Por conseguinte, entende-se por variável ecológica o conjunto de fatores ecológicos associados ou não.

A variável ecológica está associada ao macro ambiente estratégico. Dentro de uma abordagem de planejamento ela deve ser avaliada como uma oportunidade ou como uma a meaça. Contudo, a variável ecológica deve ser também incorporada à organização, como elemento essencial de sua própria cultura. A esse respeito, escrevem Santana \& Pereira (1995:699) que, para que as indústrias nāo afetem o meio ambiente de maneira negativa, destruindo-o, é necessário que a variável ecológica seja incorporada d cultura da empresa.

As preocupações com a variável ecológica há muito se fazem sentir. Fonseca (apud Tauk-Tornisielo, 1995:177) esclarece que na década de 60 , a ecologia era uma preocupação apenas de cientistas. A partir dos anos 70 é que ela passou a incorporar a pauta das discussōes internacionais. Dois fatores parecem terem sido fundamentais para esse processo: a ECO-72, em Estocolmo, e a crise do petróleo em 73 e 78.

As transformaçōes culturais ocorridas na década de 60 e 70 tiveram também consequiências na relação do homem com o meio ambiente. Conforme Donaire (1994:69), a nova consciência ambiental tornou-se um dos princípios ma is fundamentais do homem moderno.

Capra et al. (1995:25) relatam que, a partir dos anos oitenta, as empresas líderes, principalmente as alemãs, começaram a encarar os gastos com a proteção ambiental como sendo um investimento no futuro. Esse processo foi importante para que a Alemanha obtivesse um avanço como um todo, dentro da relação homem - ecologia.

Na última década, as questōes ligadas ao meio ambiente têm afetado significativamente a vida das empresas, tanto àquelas ligadas à indústria quanto àquelas ligadas ao comércio (Nahuz, 1995:56). A necessidade de proceder a Avaliação do Impacto Ambiental para novos projetos, explicada por Barbieri (1996:84), é uma dessas mudanças.

Contemporaneamente, as discussōes 


\section{PRODUÇÃO}

permeiam a necessidade do desenvolvimento sustentável. Para Pereira (1995:188), o desenvolvimento sustentável busca $o$ crescimento $e$ o desenvolvimento econômico, com a reutilização $e$ a diminuição do consumo dos recursos disponiveis, buscando o equilíbrio ecológico e a eqüidade social.

\section{O Contexto Estratégico Internacional}

O contexto estratégico no qual a variável ecológica está inserida é de certa forma ambíguo. Porter \& Van Der Linde (1995:73) esclarecem que, enquanto que por um lado há leis que contribuem para que se tenha um planeta mais habitável, por outro existe a crença de que essas mesmas leis corroem a competitividade. Ou seja, a preservação implica em incrementar os custos. Santana \& Pereira (1995:700) esclarecem que o investimento em processos produtivos ecologicamente corretos leva as empresas a majoramentos de preços que muitos concorrentes não o fazem. No caso particular da indústria têxtil, a concorrência se dá principalmente com a Ásia, uma região com poucos investimentos para a preservação dos recursos naturais. Martin \& Schumann (1997) citam uma série de exemplos, onde fica claro a falta de preocupação, tanto de empresas, quanto dos governos de países asiáticos, com relaçāo a questōes ligadas à ecologia.

Outra questão presente no contexto estratégico internacional são as barreiras não tarifárias. Considerando o mercado externo, a percepção que se tem é que a variável ecológica atende, também, outros fins. Estrategicamente é importante avaliar que, conforme Nahuz (1995:59), uma política ecológica mais severa por parte de um país importador de produtos brasileiros pode traduzir-se em uma tentativa de levantar barreiras às exportaçóes nacionais. Mas como é difícil avaliar quando a barreira existe per se, ou quando é uma tendência do mercado, não resta muito às empresas nacionais senão adaptarem-se a essas barreiras.

Também existem tendências e elas são explícitas. Maimon (1994:122) a firma que na Alemanha $80 \%$ das médias e grandes empresas têm divisão ambiental, $e$ na França esse número não supera a marca dos $20 \%$. Segundo a autora, isso se deve ao fato de que a performance a mbiental depende da regulação dos órgãos competentes e da pressão da comunidade local.

Dessa forma, as exportações para a Alemanha sofrem uma pressão direta com relação ao tra to com o meio ambiente. Pereira (1995:192) esclarece que os negócios com aquele país acabam tornando-se fatores incentivadores para procedimentos ambientais corretos.

Diante dessa postura, a Alemanha tomou a frente dos Ecobusiness. Maimon (1992:79) relata que com o fato de ter adotado o critério ecológico para a competitividade industrial, o país tornou-se líder em vendas tanto de produtos com endosso ecológico quanto de tecnologias limpas. Capra et al.(1995:25) explica por que ampliou-se a consciência ecológica a nivel de consumidor final alemão. 
crescimento da consciência ecológica atingiu várias funçōes do cotidiano daquele país. Hering $(1989: 60 ; 220)$, destaca entre outras coisas o desenvolvimento do Partido Verde dentro da Alemanha e como ele atingiu grande expressão política.

Existem dados que comprovam que o mercado internacional desenvolve em vários pontos anseios ecológicos. Maimon (1994:125) fornece informaçōes concernentes aos Estados Unidos. Em $1985,0,5 \%$ dos produtos introduzidos naquele mercado eram considerados verdes. Em 1990 esse número pulou para $9,2 \%$. Em pesquisa feita pelo Instituto Gallup em 22 países, $53 \%$ dos entrevistados estaria disposto a pagar mais por produtos que levassem em conta a proteção ambiental. No Brasil esse número seria $71 \%$ (Id.Ib.).

Santana \& Pereira (1995:701) confirmam essa tendência de consumo. Para os autores, em um futuro próximo, haverá exigências de produtos de alta qualidade e ecologicamente corretos e mudanças tecnológicas cada vez mais rápidas. A maneira para amenizar esse processo, é desenvolver dentro do contexto estratégico, a idéia de produtos com qualidade ambiental, continuam os autores. Ou, como sugere Donaire (1994), é necessário, então, um reposicionamento por parte das empresas, de sua interação com o meio ambiente completa.

Para conseguir mais competitividade dentro desse contexto, Porter \& Van Der Linde (1995) recomendam a diferenciaçāo. Os autores demonstram que os custos de adequação à legislaçāo ambiental podem ser baixados ou até mesmo neutralizados diante de inovações que tragam benefícios competitivos. Essas inovações vão conseqüentemente gerar diferenciaçōes. Já que apenas possuir os recursos deixou de ser o bastante, os autores alertam para o fato de que se tem que usá-los competitivamente.

\section{Visão Estratégica e Ações Ecológicas na Hering}

A Hering Têxtil foi fundada em 1880 , na cidade de Blumenau, Santa Catarina. A visão ecológica surgiu concomitante à fundação. $\mathrm{Na}$ época, a região possuía uma extensa cobertura de Mata Atlântica. Assim mesmo, logo nos primeiros anos a empresa desenvolvia atividades ligadas ao reflorestamento.

Entre os fatos a destacar está o de um dos fundadores da empresa, Bruno Hering, ter recebido o título de pioneiro nas atividades em favor da preservação da natureza em terras brasileiras por, entre outras coisas, ter promovido o reflorestamento em terrenos da fábrica, como descrito na obra $A$ Hering de Blumenau: um século (Hering Têxtil S/A, 1980).

Aquele passo hoje pode ser considerado corriqueiro, em termos de indústria têxtil, já que praticamente todas as grandes empresas têm seu próprio reflorestamento. Ele, no entanto, tem uma grande repercussão. Tratava-se de uma época onde preservação da natureza era um assunto completamente estranho para os contemporâneos dos Hering. Estavam 


\section{PRODUÇÃO}

falando e fazendo coisas que para os outros colonos e até mesmo para os outros pequenos industria is parecia não ter o menor sentindo. Afinal, a floresta era muito densa e muito extensa. Não havia qualquer necessidade de explorar racionalmente os recursos.

Por outro lado, essa atitude serviu para definir a relação da empresa com o meio ambiente. Desde então, ela passou a ter a ecologia como um dos mais fervorosos valores de sua cultura organizacional.

As primeiras relações com a Ecologia, como já descrito, foram voltadas ao reflorestamento. Ao que parece havia uma certa preocupação com a reposição dos estoques de lenha consumidos pelo processo industrial. Isso permaneceu como uma constante .

Mais recentemente, as alternativas relacionadas ao meio ambiente foram múltiplas. Primeiramente, para os efluentes foram feitos estudos de tratamento físicoquímico. Esses, porém, inviabilizaram-se em função, principalmente, do alto custo. Tentou-se ainda um tratamento que funcionava por valas de filtragem. A ineficácia desse sistema foi detectada, uma vez que ela incrementava a poluição do solo. Atualmente se adota o tratamento biológico que, segundo a empresa, tem apresentado ótimos resultados.

Todas essas ações se deram ao longo das décadas de setenta e oitenta, ao mesmo tempo em que a empresa continuou com o reflorestamento. Essas ações culminaram em 1995 com o lançamento do programa Gestão Ambiental. Ele objetivava conscientizar e capacitar a empresa para questões ambientais, proporcionando ações que eliminassem ou reduzissem os impactos provenientes de suas atividades (Hering Têxtil, 1995:2).

$\mathrm{Na}$ época em que a empresa elaborou o programa, ele baseava-se nas orientaçōes da ISO 14000 , mesmo sem que ela estivesse regulamentada. Segundo Nahuz (1995), as regras da ISO 14000 devem harmonizar as normas nacionais $e$ as regionais existentes, em uma linguagem única e internacional. A empresa se orientou nela para alcançar padrōes de excelência na gestão ambiental. Outra baliza usada foi a própria legislação brasileira, bem como a legislação ambiental do Estado de Santa Catarina, que se mostra como uma das mais avançadas, em termos de utilização racional dos recursos naturais.

De modo geral, os alvos do gerenciamento ambiental na Hering são (Hering Têxtil S/A, 1995):

- Investimentos em máquinas que otimizem a relação com o meio ambiente (menor consumo de energia, menor geração de efluentes, menor ruído etc.);

- Emprego de substâncias ecologicamente corretas;

- Orientação da ação a mbiental dos fornecedores;

- Segurança dos colaboradores no manuseio de produtos químicos;

- Conservação e recuperação de enengia;

- Preparação das caldeiras para a substituição da lenha e do óleo pelo gás natural;

- Controle sobre o consumo e qualidade da água;

- Cuidados com a embalagem;

- Reciclagem do lixo interno; 
- Educação ambiental dos municipal. A fim de obter um colaboradores;

- Controle das emissōes para a atmosfera;

- Controle das emissões líquidas;

- Controle da contaminação do solo;

- Sólidos e outros tipos de lixo;

- Uso da terra, da água, de fontes de enengia e fontes naturais;

- Ruído, odor e vibraçōes; e

- O efeitos em partes específicas do meio ambiente e ecossistema.

Todos os alvos assinalados anteriormente visam aprimorar a relação da empresa com o meio ambiente ecológico, em diversas fases do processo industrial. Considerando três fases distintas nas açōes ligadas à variável ecológica, em termos de técnicas e processos industriais, citadas por Maimon (1992:85), tem-se:

- primeira geração - tecnologias ligadas a equipamentos de despoluição, acopladas ao final da linha;

- segunda geração - denominadas tecnologias limpas, têm caráter preventivo e estão ligadas a redefinição de processos de produção e composição de insumos;

- terccira geração -.substituem os produtos altamente tóxicos e de consumo difundido por outros menos poluentes.

Essa referência serve para se fazer uma análise na Hering. Com uma estação de tratamento de efluentes praticamente montada, a empresa reșolve o problema de emissāo de efluentes, o que se traduziria em uma tecnologia de primeira geração. $O$ que está pendente nesse contexto é o tratamento do resíduo sólido, que atualmente é lançado no aterro sanitário enquadramento nas regras ISO 14000 , a Hering já estuda outras alternativas para esses dejetos. Está-se fazendo estudos para a diminuição de emissāo desses resíduos.

Dentro do controle de processo, a empresa resolveu eliminar um procedimento - a mercerização - que, por ser à base de soda, causava grande impacto no meio ambiente. Apesar desse tratamento agregar valor ao produto final, já que enobrece o acabamento, as ações voltadas à preservação do ambiente inviabilizariam a manutenção do mesmo. Esse procedimento pode ser considerado como de segunda geração.

Em relação à matéria-prima, ou seja tecnologia de terceira geração, foi eliminado um corante vermelho, à base de Naftol, um agente químico bastante nocivo, e de difícil biodegradação. Com isso se extingue uma parte dos transtornos causados por elementos químicos, nas águas industriais.

Essas ações parecem ser relativamente limitadas em um contexto de complexidade, como a discussão da variável ecológica exige. No entanto ela se enquadra bem à realidade vivida pela empresa. Essa idéia é corroborada pelo fato da empresa possuir uma unidade na Espanha, empregando 250 funcionários. Todo o projeto ambiental segue os padrões brasileiros. Ao contrário do que se pode pensar, os indicadores usados aqui, possuem padrões de exigência superiores àqueles utilizados naquele país. 


\subsection{Planejamento e Ecologia}

A Hering Têxtil possui uma estrutura de planejamento do tipo participativo representativo, onde os diversos setores são representados dentro do processo de planejamento. O planejamento é realizado a nualmente e sua característica básica é a orientação para o mercado. A questão da ecologia, ao contrário, é orientada por um programa à parte, mesmo porque sua dimensão de tempo é superior àquela utilizada no planejamento.

Guima rāes et al. (1995:75) esclá recem que quando o governo é incapaz de fazer cumprir as leis referentes à ecologia, o incentivo que as empresas têm para fazê-lo são a consciência social e as exigências do próprio mercado. Dentro de um ponto de vista de análise do contexto contemporâneo, é interessante avaliar as conclusões às quais se chegou na empresa, a partir de sua relação com o os órgãos governa mentais e o mercado.

A variável ecológica assume um caráter eminentemente de ameaça, desde o ponto de vista da fiscalização por órgãos governamentais, como é o caso da FATMA (órgāo do Estado de Santa Catarina encarregado da proteção ambiental). Assim, a falta de açōes para defesa do meio ambiente podem onerar a empresa, já que a FATMA atua como repressor, multando os infratores. Guimarāes et al. (1995:77) escrevem que, para órgãos como a FATMA, existe a exigência de que as empresas atuem mais harmoniosamente com relação ao meio ambiente, ao mesmo tempo em que há a geração de recursos a fim de ampliar sua faixa de atuação.

Por outro lado, como existem clientes, principalmente os alemães, que se interessam pela preservação, as ações em favor do meio ambiente podem ser consideradas como uma oportunidade. Historicamente, e como já assinalado, existe uma propensão muito forte dos alemães de maneira geral, em preocuparem-se com a exploração racional dos recursos naturais. Alguns desses clientes, segundo a empresa, chegam até a enviar inspetores para conhecer os procedimentos ligados à área ambiental. A oportunidade verifica-se claramente à medida que eles têm na Hering um fornecedor que se esforça para ser ecologicamente correto.

Da mesma forma, é importante frisar que esses clientes nāo estāo necessariamente dispostos a pagar mais para ter um produto menos nocivo à natureza. Isso significa que se tem que ser ecológico ao mesmo tempo que é mister manter os custos baixos. Aparece aí a dicotomia que já foi descrita anteriormente.

$\mathrm{Na}$ Hering os recursos aplicados com a ecologia, como apresentado no quadro 1 , já chegaram a grande monta. A previsão inicial, realizada em 1995 , para os investimentos na área de ecologia da Hering, era de US $\$ 1.005 .810,00$. Essa previsão foi em muito superada. Onde então estaria a vantagem em se aplicar um volume de recursos tão significativo na preservação do meio ambiente? No presente não se consegue necessariamente competir de igual para igual com aquelas empresas que não possuem qualquer tratamento $\mathrm{em}$ relação à conservação dos 
recursos naturais, já que os mesmos não preço final do produto. possuem custos extras a contabilizar no

Quadro 1: investimentos da Hering na área ambiental

\begin{tabular}{|c|c|c|}
\hline $\begin{array}{c}\text { Periodo } \\
1990-1994\end{array}$ & $\begin{array}{c}\text { Período } \\
1995-1997^{*}\end{array}$ & Total Geral \\
\hline $4.916 .500,00$ & $3.684 .514,00$ & $8.601 .014,00$ \\
\hline
\end{tabular}

* Para o ano de 1997, a estimativa foi de US\$1.000.000,00. Os Dados dos anos 199596 já são os reais.

Fonte: Hering Têxtil S/A 1995; Assessoria de Relaçōes Públicas. Elaboração: V.E.H, 1998.

A vantagem existiria na visão de longo prazo. Hoje sabe-se que já existem no mercado clientes com preocupaçōes ligadas à Ecologia. Percebe-se também que esse número está crescendo. Avalia-se que os recursos são limitados e, eles fa rão pressão para que aumente o número de clientes preocupados com a Ecologia. Percebe-se, então, que a Hering está se antecipando a uma tendência quase que inequívoca na relação cliente/fornecedor.

É possível prever que, em funçāo de todos esses acontecimentos, o tratamento com a ecologia será um fator que garantirá a continuidade da empresa em mercados mais sofisticados. Como a firmado por Pereira (1995:193), a normalização da série ISO 14000 servirá de base para promover o protecionismo europeu. Assim as empresas que possuírem a certificação da série ISO 14000 esta rão mais habilitadas a comercializar com a União Européia. Um dos objetivos da Hering era conseguir a certificação, tão logo ela fosse ratificada, enquanto visão estratégica, seus procedimentos estão corretos.

Embora não se tenha parâmetros para avaliar, a Hering acredita que os investimentos feitos até o momento se justificaram, uma vez que existe o lado da repressão, pelos órgāos govemamentais, $\mathrm{e}$ existe ta mbém o lado de valorização institucional, tanto junto às comunidades onde estão localizadas as unidades da empresa, quanto junto aos clientes. 


\section{PRODUÇÃO}

Talvez seja ainda muito prematuro falar em retorno, já que esse é um tipo de investimento que tem seu pay back no longo prazo. É preciso entender também que se vive uma relação de maturação, quanto a questão ambiental. As pessoas cada vez ma is vão se conscientizando da importância do consumo racional. Isso não ocorre da noite para o dia. Muitas vezes é necessário que uma nova geração venha, para então ter uma valorização desse tipo de aspecto.

\subsection{Concorrência}

Em um primeiro momento existe uma desvantagem competitiva liga da à causa ambiental, entre um agente submetido a regulamentações e outro isento delas (Almeida apud Tauk-Tornisielo, 1995:28). A autora continua, explicando que isso se deve a dois fatos principais:

1) O cumprimento de regulações implica em ampliação dos custos. Embora a adoçāo de processos mais limpos, podem gerar economia de insumos;

2) o país com uma política ambiental mais tolerante, pode estar praticando o dumping ecológico, e por isso mesmo deve estar sujeito a medidas compensa tórias como tarifas aduaneiras, proibições de importação, etc.

A empresa possui apenas uma linha de produção. Nela são fabricados tanto os produtos destinados ao mercado interno, cerca de $70 \%$ da produção, e aqueles destinados ao mercado externo, $30 \%$ do total. Assim, qualquer melhoria que se implante no sentido a incrementar as relações com o meio ambiente, atingem tanto as mercadorias destinadas ao consumidor nacional, como àquelas destinadas ao exterior.

Mais uma vez, nesse ponto cabe uma discussâo. A tendência em relação à maturação da variável ecológica ligada ao dia a dia das pessoas também é diversa aqui no Brasil. Embora pesquisas mostrem a disposição dos clientes a consumirem produtos ecologicamente corretos, sabe-se que os consumidores irāo preferir produtos ecológicos desde que eles tenham preços competitivos. Isso significa que, em funçāo do momento político-econômico que se vive hoje no país, o preço é um fator significativamente importante, no que tange a decisão da compra. Estariam melhor posicionados aqueles produtos que tiverem custos mais baixos. Como essas atividades agregam custos, sem necessariamente agregar valor, em funçāo da conjuntura, automaticamente, esses benefícios se neutralizariam.

No mercado externo, os principais concorrentes da Hering são os Estados Unidos e os Tigres Asiáticos. Os Americanos são conbecidos por sua exacerbada preocupação com relação à Ecologia nos outros países, sem contudo, apresentar o mesmo rigor internamente. $O$ que significa uma legislação mais amena $\mathrm{e}$ uma relação com o meio ambiente ecológico muito mais exploratória do que mantenedora. Quando se trata dos Tigres Asiáticos, tem-se um resultado ainda pior. Esses países são conhecidos por experimentarem um crescimento econômico recente. Nessa primeira fase, o sistema mostra-se eminentemente consumidor de recursos, sem, todavia, preocupar-se com a 
manutenção dos mesmos. A repercussão é uma degradação rápida do meio ambiente, ao mesmo tempo que se consegue vantagens internacionais principalmente ligadas aos preços finais, já que nāo está incorporada nenhuma variável do custo da exploraçāo ambientaî.

No mercado interno, existe um grande número de pequenos e médios concorrentes. Esses por sua vez possuem uma vantagem clara com relação aos grandes fornecedores. O nível de exigência e de fiscalização por parte de órgãos governamentais é menor. Isso facilita a exploração do meio ambiente, favorecendo um preço mais competitivo. Ao mesmo tempo que eles podem localizarem-se em qualquer parte, já que os recursos de que necessitam são relativamente limitados. Não necessitam, por exemplo, de grande volume de água. As grandes empresas já precisam estabelecerem-se em um ambiente que propicie o auto abastecimento de água, um dos principais recursos do processo produtivo, usado tanto para as lavações, como também para a geração de vapores, em geral.

No caso dos concorrentes externos, a empresa aposta no fato de que os fornecedores que possuírem certificados ambientais, como o ISO 14000 obtenham vantagens competitivas, nos mercados mais desenvolvidos. Um passo importante nessa direção foi conseguir dois certificados alemães: o Eco-tex, emitido pela associação Eco-tex, de Köln e o Öko-tex, de Bönnigheim. Esses são dois rótulos ecológicos, ou os assim chamados selos verdes, segundo Nabuz (1995:56-7), surgiram a partir de 1978, em função da necessidade de que se identificassem produtos e processos de pouco ou nenhum impacto ambiental. Continua o autor, que pelo fato dele ser uma premiação, acaba tornando-se um instrumento de marketing das empresas.

No mercado nacional, é necessá rio aguardar a evolução do conceito da ecologia junto ao consumidor final. Ao mesmo tempo, tenta-se explorar mais o marketing institucional. Com relação a isso, o principal problema é que não se consegue avaliar o que significam, em termos de marca ou de lembrança na mente do consumidor, as açōes dentro da perspectiva ecológica.

\section{Considerações Finais}

O final desse século traz novos desafios para a humanidade. Há a necessidade de continuar a crescer, ao mesmo tempo que manter relações mais racionais com os recursos naturais. Já que, como abordado por Sachs (apud Pereira, 1995:189), não se pode deixar de crescer. Para o autor, o desenvolvimento sustentável tem que ser socialmente desejável, economicamente viável e ecologicamente prudente.

Infelizmente, um comportamento ma is pró-ativo e ético em relação ao meio ambiente, não é a regra nem nos países desenvolvidos (Maimon, 1994:121). Com o agravamento das disputas por mercados internacionais, os recursos continuam a serem consumidos sem uma preocupação com sua possível escassez. Mas o desenvolvimento não se mantém se a base dos recursos ambientais se deteriora (Nosso Futuro Comum apud 
Pereira, 1995:189).

Como o nível de pressão sobre países como o Brasil tem se elevado consideravelmente, nas empresas tem surgido uma grande preocupação relacionada às questōes ambientais.

Dessa maneira, as estratégias ligadas à variável ambiental geralmente estão ligadas a sina is positivos por parte do mercado. Os custos e os aspectos mercadológicos ainda são fatores decisivos para as empresas (Maimon, 1992:75).

Guima rāes et al.(1995:80), afirmam que aqueles que nāo conseguirem se adaptar deixarão o mercado, não por imposição governamental e sim por que perderão competitividade, já que as novas exigências dos consumjdores nāo sancionarāo produtos e serviços ecologicamente suspeitos. Assim, a variável ecológica acaba se tomando um fator limitante para a participaçāo das empresas em mercado com potencial maior.

A fim de conseguir uma alteração significativa na interação empresa/ a mbiente, faz-se necessário mudanças à nível de cultura organizacional. Capra et al. (1995:87) chamam a atenção para a necessidade de promover uma mudança na cultura empresarial, a fim de se alcançar uma melhoria significativa no impacto ecológico das operaçōes da empresa.

O caso da Hering contradiz os casos estudados por Donaire (1994:75), já que o mesmo afirma que naqueles casos a interiorizaçāo da variável ecológica se deu em função de influências externas em um primeiro momento, que resulta ram em repercussōes ao nivel interno.

$\mathrm{Na}$ Hering o surgimento de uma cultura ecológica foi concomitante à fundação. Talvez por isso o assunto é tratado com naturalidade pela empresa. Não há destaques quanto ao planejamento estratégico, embora o assunto seja considerado estrategicamente.

Isso significa que a empresa tem preocupaçóes ecológicas, ao mesmo tempo que consegue enxengar as oportunidades e ameaças que a questāo fomenta. Do lado das ameaças, está o fa to das sanções governamentais, que podem, e muito, onerar uma empresa daquele porte. Por outro lado, existe também as condiçōes que a levam a avaliar as oportunidades. Alguns mercados mais desenvolvidos já criaram sistemas complexos de restriçōes no âmbito a mbiental, que com o tempo eliminarão do mercado aqueles que não tiverem uma posição positiva dentro do contexto ecológico.

A visão de Porter \& Van der Linde (1995:73) corroboram essa idéia. Para os autores novos padrōes ambientais podem gerar inovaçōes que diminuam o custo ou agreguem valor ao produto, já que as inovações permitem que se use mais racionalmente uma série de insumos, compensando os investimentos feitos. Dentro de uma visão de longo prazo a Hering vislumbra vantagens competitivas maiores do que aquelas que possui hoje.

Considerando ainda o fato da empresa ter trabalhando com afinco no sentido de conseguir uma certificação ambiental da série ISO 14000 , conquistada em abril de 1997, ela se tornou uma das pioneiras em seu ramo de atividade. Esforços e investimentos foram feitos para se chegar a esse objetivo. 
O futuro dependerá das açōes presentes. As tecnologias que podem auxiliar já existem. Ao menos parte delas. A variável ecológica pode ser associada tanto à manutenção, no futuro de um estado presente, quanto a ampliação desse, através do reconhecimento por parte dos consumidores de valores ligados à ecologia (Odum, 1988:341-7).

Os produtos Hering têm seguido projetos cada vez mais ecologicamente corretos. Hoje está se procurando aperfeiçoar o projeto de um plástico fotodegradável, já que também a embalagem faz parte do produto.

Acreditando em valores como esses é que a Hering pretende ser mais do que a empresa dos "dois peixinhos". Ela quer se posicionar nāo como uma empresa preocupada com a preservação do meio ambiente e sim, como uma empresa que age em favor da preservação da vida.

Recebido em: 04/04/97

Recebido após modificaçōes: 23/04/98

Aceito em: $12 / 11 / 98$

Publicado em: 25/03/99

\section{Referências Bibliográficas}

ALVES, Alda J. O planejamento de pesquisas qualitativas em educação. Caderno de pesquisa. v.77, p.53-61, maio 1991.

ALVES, Zélia M. M. B. Intersecçōes das análises quantitativas e qualitativas. 1988.

BARBIERI, J.C. Avaliação de impacto ambiental na legislaçāo brasileria In: $\underline{\mathrm{RAE}}$.
São Paulo, v.35, n.2, p.78-85, mar/abr 1996.

CAPRA, F. et al. Gerenciamento ecológico: ecomanagement. São Paulo: Cultrix, 1995. 203p.

CONTADOR, J.C. Armas da competiçāo. In: RAUSP, São Paulo, v.30, n.2, p.50-64, abr/jun 1995.

DAJOZ, R. Ecologia geral. Petrópolis: Vozes, 1983. 472p.

DELAZARO, W. \& BARBIERI, J.C. Geração de emprego e preservação do meio a mbiente: o grande desafio. In: RAE. São Paulo, v.34, n.6, p.73-79, nov/dez 1994.

DONAIRE, D. Consideraçōes sobre a variável ambiental na empresa. In: RAE. São Paulo, v.34, n.2, p.68-77, mar/abr. 1994.

GODOY, Arilda Schmidt. Introdução à pesquisa qualitativa e suas possibilidades. In: RAE. São Paulo, v.35, n.2, p.57-63, mar./abr. 1995.

. Pesquisa qualitativa: tipos

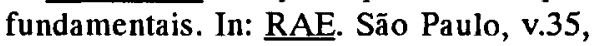
n.3, p.20-29, mai/jun. 1995a.

A pesquisda qualitativa e sua utilização em administração de empresas. In: RAE. São Paulo, v.35, n.4, p.65-71, jul/ago. 1995 b.

GUIMARÃES, P.C.V. et al. Estratégias empresariais e instrumentos econômicos de gestāo ambiental. In: RAE. São Paulo, v.35, n.5, p.72-82, set/out 1995. 
Hering Têxtil S/A. A Hering de Blumenau: um século: $1880-1980$. São Paulo: Laborgraf, 1980. 169p. - Gestão ambiental. Blumenau,1995. 36p. Mimeo.

HERING, I.Coletânea de artigos II. São Paulo:Labongraf, 1989. 240p.

MAIMON, D. Ensaios sobre economia do meio ambiente. Rio de Janeiro:APED, 1992. 150p.

\section{Eco-estratégias nas} empresas brasilerias:realidade ou discurso? In: RAE. São Paulo, v.34, n.4, p.119-130, jul/ago 1994.

MARGALEF, R.Ecologia. Barcelona: Omega, 1991. Cap.24, p789-822.

MARTIN, Ha ns-Peter; SCHUMANN, Haral. A armadilha da globalização:(...). São Paulo: Globo, 1997.

NAHUZ, M.A.R. O sistema ISO 14000 e a certificação ambiental. In: RAE. São Paulo, v.5, n.6, p.55-66, nov/dez 1995.

ODUM, E.P. Ecologia. Rio de Janeiro:
Guanabara, 1988. 436p.

PEREIRA, M.F. As empresas em busca de tecnologias ambiental limpas em bases sustentáveis. In: Revista Brasileira de Administracão/ANPAD. Rio de Janeiro, v.1, n.7, p.187-204, 1995.

PORTER, M. E. \& VAN DER LINDE, C. Ser verde também é ser competitivo. In: Revista Exame. Ed.567, São Paulo, n.24, p.72-78, 22 nov 1995.

SANTANA, E.A. de. \& PEREIRA, M.F. Desenvolvimento sustentável: uma contribuição para a competitividade industrial. In: Congresso Nacional de Engenharia de Produção - ENEGEP 95. Anais(...). São Carlos:UFScar, 1995. p.697701.

TAUK-TORNISIELO, S.M. et al.(organizadores). Análise a mbiental: estratégias e ações. São Paulo: T.A. Queiroz; Fundação Salim Farah Maluf, 1995, 381p.

Análise ambiental: uma visāo multidisciplinar. 2.ed. São Paulo:Ed. da Universidade estadual Paulista, 1995. 207p. 